\title{
PROJETO DE UMA MÁQUINA DE FLUXO TANGENCIAL DE FABRICAÇÃO SIMPLIFICADA ${ }^{1}$
}

\author{
Carlos Henrique Lagemann², Rafael Farias Garcia ${ }^{3}$, Guilherme Leite Lago ${ }^{4}$
}

Resumo: O crescimento da cadeia produtiva brasileira gera uma demanda cada vez maior de energia para suprir as necessidades dos processos industriais. Este crescimento torna necessário um maior investimento em pesquisas para a otimização de processos produtivos, tornando-os autossustentáveis. É neste sentido, que o presente estudo tem como principal objetivo a realização de um projeto, sua execução e análise de uma máquina de fluxo tangencial de fabricação simplificada. Para tanto, foram utilizadas as principais teorias de mecânica dos fluidos e fundamentos da termodinâmica, bem como as principais etapas de um projeto de Engenharia Mecânica, visando à otimização do sistema. Utilizando a metodologia desenvolvida, foi possível atingir em todos os testes realizados o objetivo principal deste trabalho, que foi a geração de potência mecânica no eixo de $1.000 \mathrm{~W}$. Desta forma realizou-se um comparativo com o dimensionamento básico realizado na fase inicial do projeto, apresentando uma eficiência de $18,63 \%$, o que para este caso foi considerado satisfatório.

Palavras-chave: Máquina de fluxo. Cogeração. Sustentabilidade.

\section{INTRODUÇÃO}

Com a grande demanda de energia para o desenvolvimento das indústrias, faz-se necessária a geração de energias suplementares focadas no reaproveitamento de fontes energéticas e no aumento da eficiência dos

1 Resumo de Trabalho de Conclusão do Curso de Engenharia Mecânica do Centro Universitário UNIVATES. Acadêmico Rafael Farias Garcia, orientador Lober Hermany e co-orientador Carlos Henrique Lagemann.

2 Mestre em Engenharia pela Universidade Federal do Rio Grande do Sul (UFRGS), Porto Alegre, RS, Brasil. Professor do curso de Engenharia Mecânica da Univates, Lajeado, RS, Brasil. E-mail: chlagemann@univates.br

3 Acadêmico do curso de Engenharia Mecânica da Univates, Lajeado, RS, Brasil. E-mail: rafafg1985@gmail.com

4 Acadêmico do curso de Engenharia Mecânica da Univates, Lajeado, RS, Brasil. E-mail: rafafg1985@gmail.com 
processos produtivos. As máquinas de fluxo possuem configurações para atender estas necessidades que visam à produção de trabalho útil através de fontes energéticas alternativas, as quais podem ser utilizadas obtendo alta produtividade a baixo custo, inovação e sustentabilidade.

Souza (2011), destaca que o projeto de máquinas de fluxo, como em qualquer outro projeto, tem por objetivo atender todas as expectativas estabelecidas inicialmente. Neste caso, a expectativa é transformar a energia da quantidade de movimento do fluido, seja um fluido pneumático ou hidráulico, em trabalho mecânico. Para que esta necessidade seja atendida, é necessário que haja uma interação adequada entre as teorias e os dados de entrada do projeto, proporcionando um plano de escala adequado, no qual permitirá que seja concretizado o modelo ou protótipo proposto. Este modelo é testado severamente, almejando a sua validação.

O presente trabalho contempla o desenvolvimento de uma máquina de fluxo tangencial, que por receber a energia cinética do escoamento do fluido, também pode ser chamada de máquinas de fluxo motora, ou seja, o fluidoé quem fornece energia para o rotor, transformando a energia cinética do escoamento do fluido em energia mecânica no eixo da máquina de fluxo. Segundo Henn (2010), as principais aplicações das máquinas de fluxo tangenciais são na geração de energia elétrica através das turbinas hidráulicas, as mais comuns são conhecidas como máquinas de fluxo tangencial Pelton. A metodologia aplicada possui as principais fases do projeto, que são o entendimento dos requisitos, dimensionamento básico, projeto 3D e 2D, projeto de fabricação, processos de fabricação e testes e validações. Para isso, foram aplicados os principais conceitos da termodinâmica e mecânica dos fluidos, buscando a geração de $1000 \mathrm{~W}$ de potência mecânica no eixo e a maior eficiência possível do sistema proposto.

\subsection{Objetivo geral}

Dimensionar, fabricar e validar através de testes práticos uma máquina de fluxo tangencial de baixo custo, buscando compreender as diversas variáveis do projeto, visando a geração de potência mecânica em um eixo.

\subsection{Delimitação do trabalho}

Este trabalho foi restrito ao desenvolvimento teórico e prático de uma máquina de fluxo tangencial. $\mathrm{O}$ baixo custo está relacionado à facilidade de fabricação que o modelo proposto oferece e não houve um detalhamento dos custos envolvidos no processo. As validações experimentais foram realizadas através de uma linha de ar comprimido. Não foram realizados estudos aprofundados dos materiais envolvidos no projeto, o estudo de materiais depende do tipo de fluido aplicado na máquina. Este trabalho está relacionado apenas ao desenvolvimento de uma máquina de fluxo com escoamento 
tangencial em relação ao rotor, sendo que as demais configurações de máquinas de fluxo não serão apresentadas ou discutidas neste trabalho. Não foram apresentados detalhes dos equipamentos instalados no sistema para a validação do projeto. Foram apresentados de forma detalhada somente os componentes de uma máquina de fluxo que influenciam de uma forma significativa nos aspectos construtivos e que interferem na direção do escoamento do fluido e que são responsáveis por produzir fenômenos fluidodinâmicos que alteram a eficiência do projeto. A análise detalhada dos processos produtivos e de fornecedores também não foi contemplada.

\section{METODOLOGIA}

Segundo Souza (2011), as etapas do projeto de uma Máquina de Fluxo MF, de forma específica, de uma Máquina de Fluxo Motora - MFM, encontramse detalhadas no fluxograma a seguir (FIGURA 1).

Figura 1 - Fluxograma do projeto

\section{ATIVIDADE 1 - Entendimento dos requisitos}

ATIVIDADE 2 - Dimensionamento básico

ATIVIDADE 3 - Desenho 3D E 2D

\section{ATIVIDADE 4 - Processo de fabricação, Testes e validaçōes}

Fonte: dos autores (2016).

\subsection{Entendimento dos requisitos}

Após uma análise criteriosa das teorias existentes e estudo sobre a viabilidade econômica do projeto, máquinas operatrizes e matéria prima disponível, determinou-se como principal dado de entrada, uma máquina de fluxo tangencial de baixo custo com rotor de $300 \mathrm{~mm}$ de diâmetro, 3500 rotações por minuto no eixo e com a geração de $1000 \mathrm{~W}$ de potência mecânica no eixo. 


\subsection{Dimensionamento básico}

De acordo com Fox (2013), o torque teórico e a força teórica mínima para a geração de $1000 \mathrm{~W}$, podem ser obtidos por meio do arranjo das equações $1 \mathrm{e}$ 2. Neste caso, considerando apenas uma entrada e uma saída no sistema, desta forma, com a equação 1 , foi calculado o torque teórico mínimo necessário para a geração de $1000 \mathrm{~W}$ de potência mecânica no eixo, através da razão entre a potência em $(W)$ e as velocidades angular $(\omega) \mathrm{em} \mathrm{rad} / \mathrm{s}$.

$$
\mathrm{T}=\frac{\mathrm{P}}{\omega}
$$

A determinação da força mínima para a geração de $1000 \mathrm{~W}$ de potência mecânica foi calculada pela equação (2), pela razão entre torque (T) em N.m, e o raio do rotor $(\mathrm{r})$ em metros.

$$
\mathrm{F}=\frac{\mathrm{T}}{\mathrm{r}}
$$

De acordo com Çengel (2015), para determinar a força disponível no escoamento do ar de alimentação do bico injetor, é necessário conhecer a massa específica do fluido. Para o experimento do teste 1, no qual foi utilizado uma pressão manométrica de 517,10 kPa (75PSI), a massa específica foi calculada utilizando a pressão absoluta, ou seja, o somatório da pressão manométrica com a pressão atmosférica.

Com a equação (3), o cálculo da massa específica $(\rho)$ em $\left(\mathrm{kg} / \mathrm{m}^{3}\right)$, foi realizado para todas as pressões utilizadas na validação do projeto, ou seja, para cada situação houve uma pressão diferente, consequentemente, haverá uma massa específica para cada condição de teste, levando em consideração que a determinação da massa específica é a razão entre a pressão absoluta (pressão manométrica + pressão atmosférica) com o produto entre da lei universal dos gases $(\mathrm{R})$ com temperatura ambiente $(\mathrm{T})$. Para esta condição considerou-se uma temperatura ambiente de $20^{\circ} \mathrm{C}$. Os resultados dos demais testes realizados utilizando a mesma sequência de cálculos serão apresentados na Tabela 1.

$$
\rho=\frac{\mathbf{p}(\mathrm{kPa})+101.32 \mathrm{kPa}}{\mathrm{RT}}
$$

Segundo Van Wylen (2012), além da massa específica, também é necessário conhecer a velocidade do escoamento do bico injetor. O cálculo para determinar a velocidade do teste 1 foi determinado conforme a equação (4).

$$
\mathrm{v}_{2}=\sqrt{\frac{(\mathrm{p}(\mathrm{kPa}))^{2}}{\rho}}
$$

Com os valores da velocidade e da massa específica, foi possível calcular a força disponível no escoamento, para este caso utilizando a equação (5). 


$$
\begin{aligned}
& \sum \mathrm{F}=\mathrm{v} \rho \mathrm{vA} \\
& \text { Logo, } \\
& \mathrm{F}=\mathrm{v}^{2} \rho \frac{\pi \mathrm{D}_{\text {injetor }}^{2}}{4}
\end{aligned}
$$

Segundo Fox (2013), o torque ideal que seria gerado no eixo da máquina se não houvessem perdas, pode ser calculado pelo arranjo da equação de conservação da quantidade de movimento angular, equação (6).

$$
\mathrm{T}=\mathrm{Fr}_{\text {rotor }}
$$

Segundo Çengel (2011), para determinar a eficiência termodinâmica da máquina, deve-se realizar o balanço de exergia no sistema. Foi aplicada a mesma equação na seção de entrada e de saída da máquina, adequando a mesma para as condições do presente estudo, esta equação pode ser reescrita conforme a equação (7).

$$
\Delta \varphi=\frac{\mathrm{v}^{2}}{2} \dot{\mathrm{m}}
$$

Onde

$$
\dot{\mathrm{m}}=\rho Q=\rho v \frac{\pi \mathrm{D}^{2}}{4}
$$

Para a realização dos testes e validações do protótipo, foi prédeterminado a realização de três testes com três diferentes pressões. Todas as demais condições de testes realizados foram calculadas de acordo com a mesma sequência de cálculos apresentados anteriormente, nos quais os resultados podem ser encontrados na Tabela 1.

Tabela 1 - Resultados dos cálculos realizados para três situações de testes

\begin{tabular}{ccccccc}
\hline Teste & $\begin{array}{c}\text { Pressão } \\
\text { manométrica } \\
\mathbf{( k P a )}\end{array}$ & $\begin{array}{c}\text { Densidade } \\
\mathbf{(} \boldsymbol{\rho})\end{array}$ & $\begin{array}{c}\text { Velocidade } \\
\frac{\mathbf{m}}{\mathrm{s}}\end{array}$ & $\begin{array}{c}\text { Força } \\
\mathbf{( N )}\end{array}$ & $\begin{array}{c}\text { Torque } \\
\text { ideal } \\
\mathbf{( N m})\end{array}$ & $\begin{array}{c}\text { Variação da } \\
\text { exergia } \\
\mathbf{( N )}(\mathbf{w})\end{array}$ \\
\hline 1 & 517,10 & 7,353 & 375,04 & 29,24 & 4,38 & 5383,19 \\
2 & 861,86 & 11,45 & 387,96 & 48,73 & 7,31 & 9453,69 \\
3 & 1206,58 & 15,55 & 393,93 & 68,22 & 10,23 & 13438,67 \\
\hline
\end{tabular}

Fonte: dos autores (2016).

Através destes parâmetros apresentados na Tabela 1, teoricamente se consegue atender aos objetivos apresentados. Percebem-se valores expressivos na variação de exergia, ou seja, a máxima energia disponível ao sistema que pode ser convertida em trabalho, posteriormente estes valores serão comparados com 
o trabalho realizado em cada teste, podendo ser realizada a análise da eficiência do sistema para cada condição de operação. Estes parâmetros serão utilizados para os próximos passos que deram início à parte experimental de verificação.

\subsection{Projeto 3D e 2D}

Após o dimensionamento e determinação das especificações geométricas do projeto de uma máquina de fluxo tangencial de fabricação simplificada, realizaram-se os desenhos $3 \mathrm{D}$ dos elementos construtivos da máquina de fluxo tangencial em questão e dos gabaritos que foram indispensáveis para os testes e validações do protótipo. Para a realização desta atividade, foi utilizado um software em CAD. A Figura 2 apresenta uma vista explodida dos principais elementos construtivos do projeto.

Figura 2 - Vista explodida do projeto

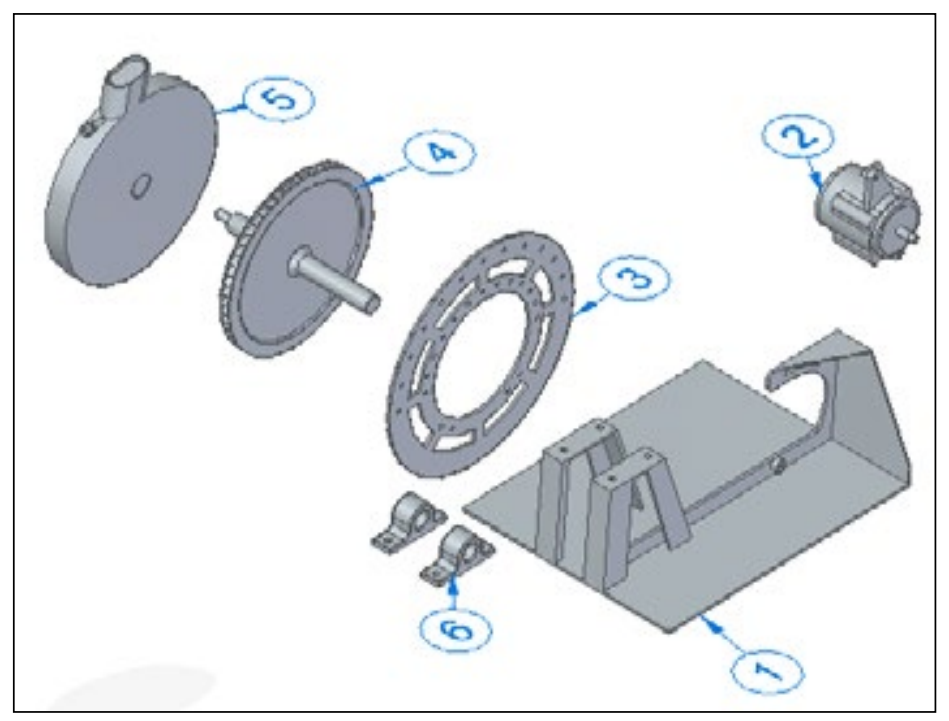

Fonte: dos autores (2016).

Nomenclatura dos principais elementos construtivos: 1 - estrutura, 2 alternador, 3 - gabarito para determinação do ângulo de entrada, 4 - rotor, 5 - carcaça e 6 - mancais.

A Figura 3 apresenta o detalhamento das principais especificações geométricas do rotor, como largura e diâmetro. O rotor é o principal elemento que compõe o sistema, e que é responsável por converter a energia cinética do escoamento do fluido em energia mecânica. 
Figura 3 - Detalhamento do rotor.

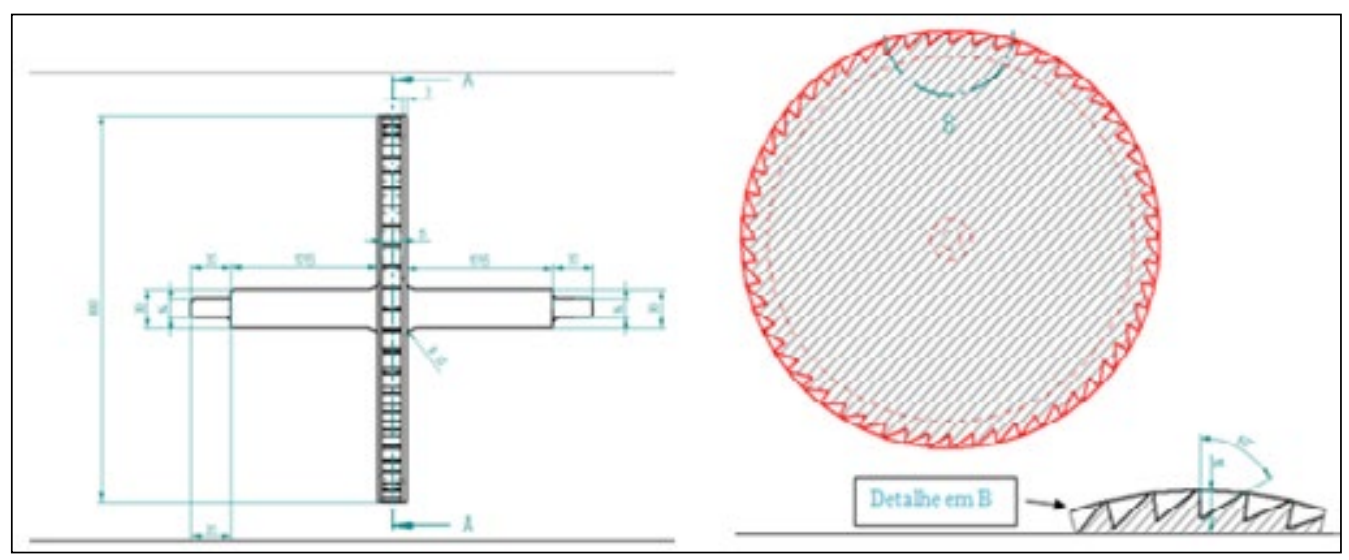

Fonte: dos autores (2016).

Um dos dados de entrada utilizado para o dimensionamento básico foi o diâmetro do rotor de $300 \mathrm{~mm}$. Partindo desta informação, o número de pás que compõem o rotor foi determinado pela relação entre o ângulo da fresa utilizada para usinagem do rotor, e a altura limite da pá, que foi de $10 \mathrm{~mm}$ até que atingisse a aresta da pá (crista) de $0,5 \mathrm{~mm}$. Consequentemente, o número de pás obtidas no rotor foi de 56.

\subsection{Processo de fabricação, Testes e validações}

Nesta etapa foram desenvolvidos gabaritos para que todas as variáveis que envolvem a eficiência e o comportamento fluidodinâmico do sistema fossem analisadas. Desta forma, foi possível a realização de testes para a determinação das melhores condições de trabalho para cada elemento do projeto, correlacionando os dados de entrada com os valores de resposta obtidos.

Os testes realizados tiveram como principal objetivo a determinação das melhores condições para as etapas a seguir:

1. Determinação da folga entre o rotor e carcaça;

2. Ângulo de entrada da carcaça;

3. Validação do diâmetro do bico injetor;

4. Ângulo de saída da carcaça;

5. Validação de potência do sistema

Para a realização dos experimentos, foi utilizado como fonte de alimentação um compressor da marca Pressure Onix Press. Este compressor possui um deslocamento teórico (vazão) de 1133 1/min e pressões de trabalho 
até $1206,58 \mathrm{kPa}$ (175 PSI), estas informações foram indispensáveis para a realização do dimensionamento básico e testes executados.

\subsubsection{Determinação da folga entre a carcaça e o rotor}

Para o entendimento do estudo de uma máquina de fluxo tangencial, inicialmente desenvolveu-se um projeto de acordo com a viabilidade de recursos financeiros e de estrutura disponível.

Baseando-se no dimensionamento básico, uma carcaça piloto foi desenvolvida para entender o comportamento do escoamento do fluido em relação à geometria proposta. Esta ação foi necessária porque não foi possível utilizar o software disponível para a simulação de fluidos, considerando que o software disponível na instituição é direcionado apenas para escoamentos laminares, neste estudo, o comportamento do escoamento deste projeto é turbulento.

Estes dispositivos também tiveram como principal objetivo a realização de testes experimentais, tendo em vista que a bibliografia consultada não aborda de forma clara problemas práticos e interações entre os elementos construtivos, além de diversas variáveis dos projetos de máquinas de fluxo que influenciam de forma significativa nos efeitos dinâmicos do sistema. Portanto, foi desenvolvida uma bancada piloto para simulação de testes dinâmicos e melhor entendimento do comportamento do escoamento do fluido entre o rotor e a carcaça.

De acordo com a figura 4, foi adaptado na estrutura um alternador de 12 Volts e 50 Amperes com o objetivo de colocar uma carga no eixo. Com isso, possibilitando a realização de testes com eixo livre (sem carga do alternador) e eixo carregado (com carga no alternador).

Figura 4 - Bancada piloto com alternador

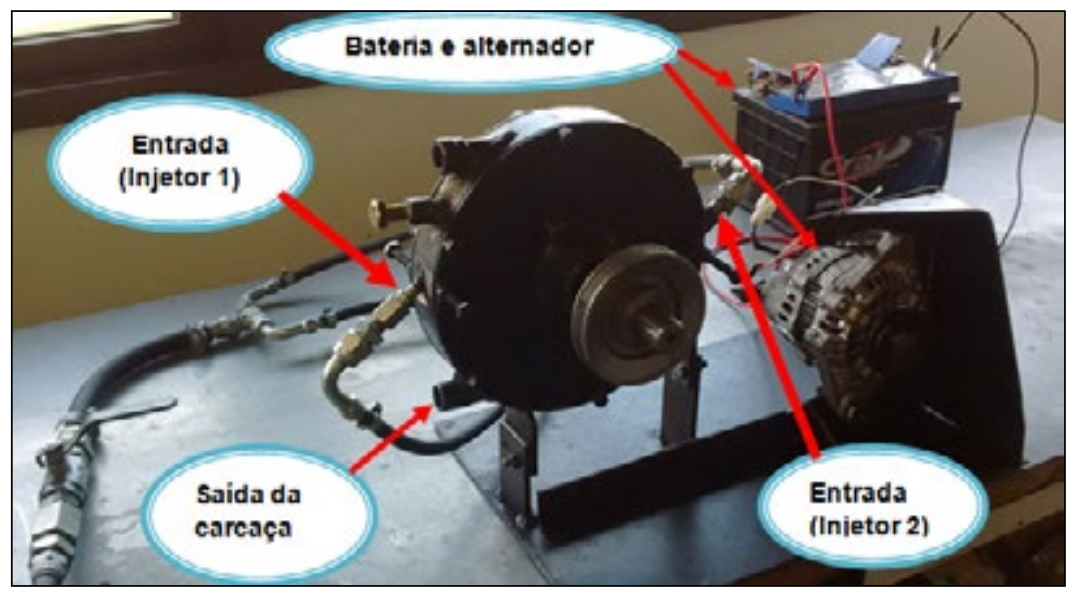

Fonte: dos autores (2016). 
Nos testes iniciais, constatou-se que mesmo nas melhores condições, nas faixas mais altas de rotação, quando foi acionado o alternador, gerando uma carga no eixo, o mesmo perdeu potência voltando para a condição estática, parando em poucos segundos após a aplicação da carga. Optou-se por fazer um ensaio destrutivo, aumentando a folga entre o rotor e a carcaça. Os testes foram repetidos, e apresentaram uma melhora significativa. Esta variável não consta na literatura consultada e o seu entendimento foi essencial para dar andamento ao trabalho. A Figura 5 ilustra a folga entre o rotor e carcaça.

Figura 5 - Folga entre o rotor e a carcaça

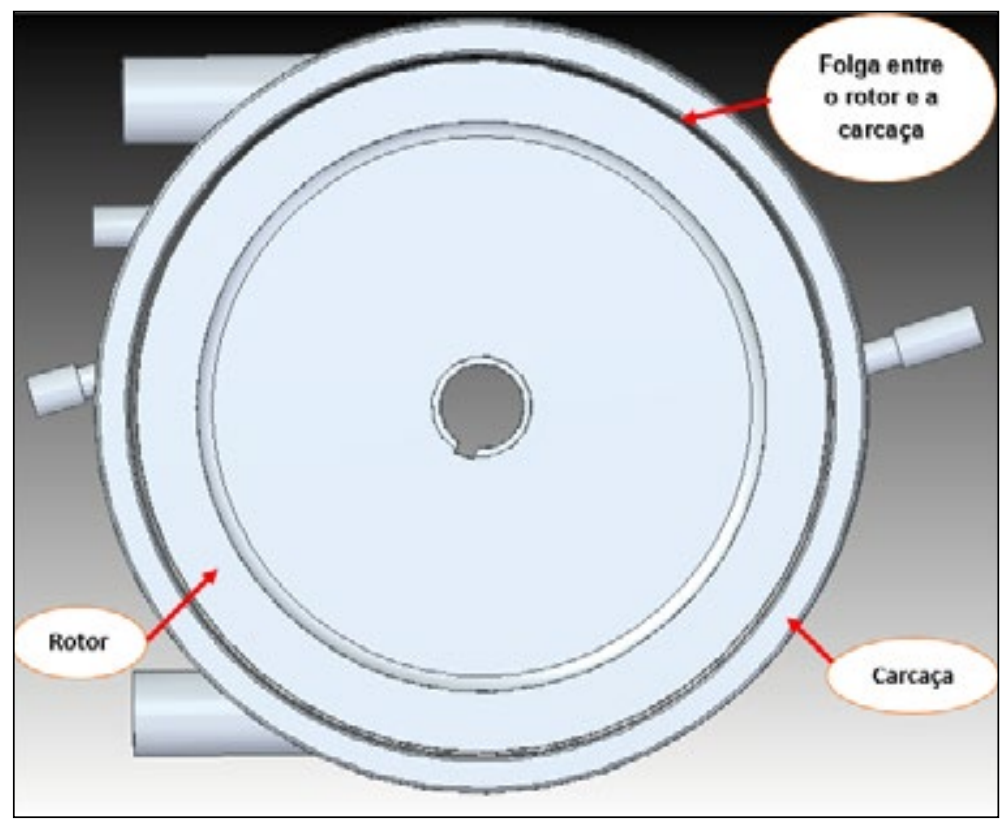

Fonte: dos autores (2016).

Em seguida foram realizados testes com a segunda entrada de ar comprimido (Injetor 2) na carcaça alimentada simultaneamente, visando auxiliar na alimentação do sistema e analisar sua influência na efetividade do mesmo. No Quadro 1, é possível entender o comportamento dos testes realizados neste experimento: 
Quadro 1 - Testes para análise da influência da folga entre o rotor e a carcaça

\begin{tabular}{|c|c|c|c|c|c|}
\hline Teste & $\begin{array}{c}\mathbf{N}^{\mathbf{0}} \\
\text { Entrada }\end{array}$ & $\begin{array}{c}\text { Faixa de pressão em PSI } \\
\text { 50 PSI - 334,7 kpa } \\
\text { 100 PSI - 689,4 kpa } \\
\mathbf{1 7 5} \text { PSI - 1206,5 kpa }\end{array}$ & $\begin{array}{c}\text { Folga } \\
\text { Raio rotor } \\
\text { /carcaça } \\
\text { Unidade em } \\
\text { mm }\end{array}$ & $\begin{array}{c}\text { RPM eixo } \\
\text { livre }\end{array}$ & $\begin{array}{c}\text { RPM eixo } \\
\text { carregado }\end{array}$ \\
\hline 1 & 1 & $100-50$ & 0,2 & 3000 & 0 \\
\hline 2 & 2 & $100-50$ & 0,2 & 4000 & 0 \\
\hline 3 & 1 & $175-50$ & 0,2 & 3500 & 0 \\
\hline 4 & 1 & $100-50$ & 0,5 & 3900 & 0 \\
\hline 5 & 2 & $100-50$ & 0,5 & 4500 & 0 \\
\hline 6 & 1 & $100-50$ & 1,5 & 5000 & 750 \\
\hline 7 & 2 & $100-50$ & 1,5 & 5500 & 1250 \\
\hline 8 & 1 & $175-50$ & 1,5 & 7000 & 3325 \\
\hline
\end{tabular}

Fonte: dos autores (2016).

Não foi possível realizar um teste com duas entradas e 1206,58 kPa, já que não havia disponibilidade de um segundo compressor com as mesmas características. $\mathrm{O}$ teste realizado foi apenas para analisar sua influência no escoamento e na determinação da folga entre o rotor e a carcaça. Para estudos futuros acredita-se que o teste com duas entradas seja um bom direcionamento com possibilidades de aumentar a eficiência do projeto.

De acordo com as informações do Quadro 1, foi possível entender que a folga entre o rotor e a carcaça influência de uma forma significativa na eficiência do sistema. Observa-se que nos testes 1, 2, 3, 4, e 5, independente da pressão utilizada, o eixo não obteve qualquer eficiência, parando rapidamente ao ser carregado e nos testes 6, 7 e 8 houve uma melhora considerável devido a uma maior folga. Com isso, testes foram realizados sem carcaça, o que evidenciou o perfeito funcionamento do sistema comprovando que a carcaça não pode influenciar no escoamento do sistema.

Com os testes realizados, pode-se afirmar que, para a configuração proposta, quanto menor a folga entre o rotor e a carcaça, maior é a possibilidade de o jato de pressão da alimentação atuar como força positiva e negativa em relação à pá do rotor, desta forma, travando o rotor. A Figura 6 apresenta de uma forma mais detalhada, a atuação de dois vetores, nos quais o vetor 1 atua como o jato de alimentação do injetor, sendo assim uma força positiva e o vetor 2 uma força negativa. Este fenômeno se dá devido ao fluido encontrar-se em estado de confinamento, escoando apenas pela mínima folga entre o rotor e a carcaça, prejudicando de uma forma contundente a eficiência do sistema. 
Figura 6 - Vetor positivo (1) e negativo (2) atuando na pá do rotor.

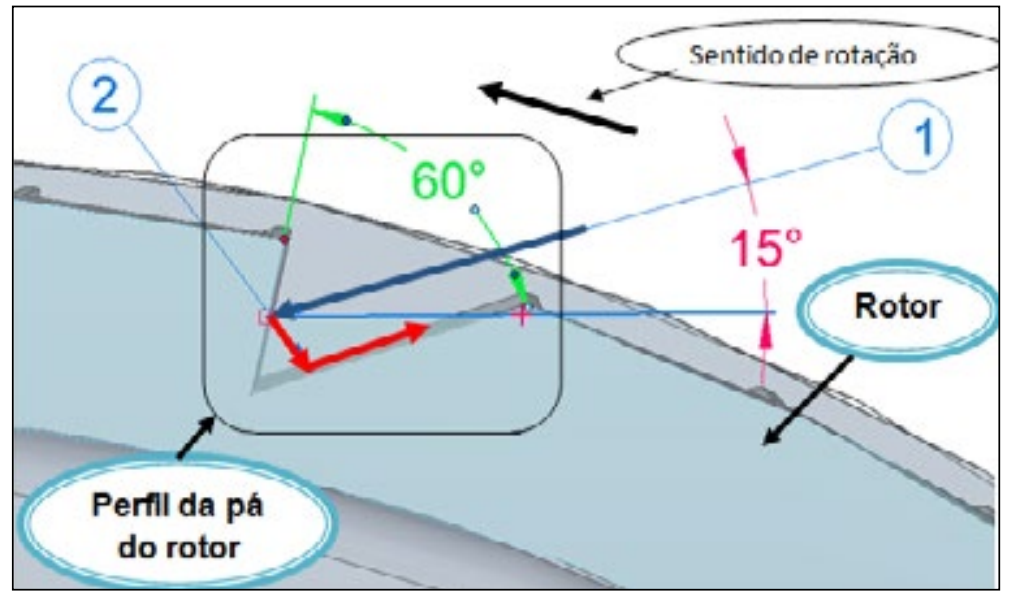

Fonte: dos autores (2016).

Com isso, ficou evidente que, para as condições do presente estudo, a carcaça não pode influenciar no escoamento do fluido, ou seja, pelo ar comprimido ter baixa densidade, no escoamento, após o jato de pressão atuar na pá do rotor, o mesmo sempre terá a tendência de sair o mais rápido possível da carcaça. Desta forma, o ângulo de saída da carcaça precisa auxiliar na saída do fluido, contribuindo para que o fluido não fique confinado. Com isso, a condição ideal para este modelo é um sistema aberto, o que foi aplicado nos testes e apresentado no decorrer com trabalho.

\subsubsection{Determinação do ângulo de entrada na carcaça}

Levando em consideração as conclusões do item anterior, para a determinação da melhor condição do ângulo de entrada na carcaça, retirouse a carcaça do protótipo. Para esta etapa, testes foram realizados com o rotor calculado no dimensionamento básico (rotor de $300 \mathrm{~mm}$ de diâmetro), de acordo com a Figura 7. 
Figura 7 - Testes realizados sem a carcaça e gabarito de disco com furações a cada $15^{\circ}$

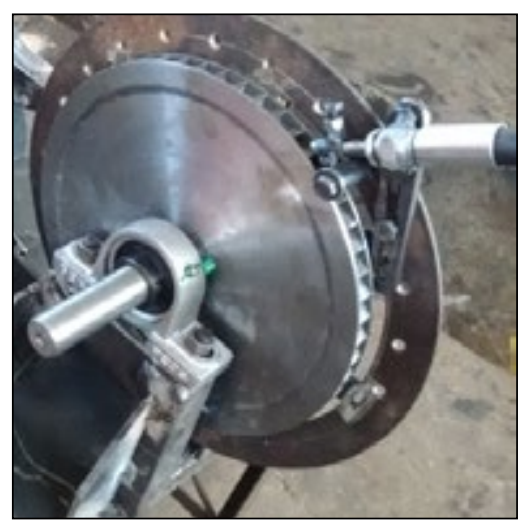

Fonte: dos autores (2016).

Instalou-se um disco ao lado do rotor com furações a cada $15^{\circ}$ conforme a Figura 7. Para cada posição do disco realizou-se testes com um ou dois ângulos, sempre posicionando a entrada do injetor de forma tangencial em relação ao rotor. O dispositivo que fixa o injetor foi projetado com um gabarito, possibilitando a articulação de forma angular, também com deslocamento axial, desta forma possibilitou uma maior aproximação do bico injetor no rotor. Com este gabarito foi possível obter o melhor aproveitamento da energia do fluido, o posicionamento do disco instalado ao lado do rotor foi determinado pelo espaço físico disponível, desta forma foi possível a realização dos testes em 13 posições definidas de acordo com a Figura 8.

Figura 8 - Numeração das posições para testes da melhor condição de ângulo de entrada

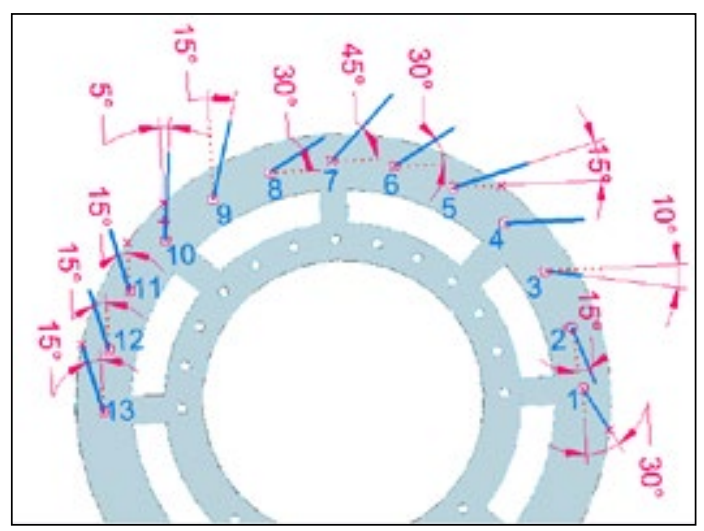

Fonte: dos autores (2016). 
Neste gabarito de furação, a partir da posição 1, observa-se que para cada posição instalou-se o bico injetor sempre visando tangenciar o rotor. Com isso, foi possível analisar a melhor condição de ângulo entrada da carcaça. Os resultados obtidos podem ser analisados na Tabela 2.

O compressor utilizado para os testes não teve condições de manter a pressão constante devido ao consumo no reservatório ser maior que a vazão gerada simultaneamente. Desta forma, determinou-se um parâmetro para todos os testes, estipulou-se uma variação de pressão de $344,73 \mathrm{kPa}$ (50 PSI) para todas as análises, sempre acionando o injetor através de uma válvula quando o manômetro atingisse $689,47 \mathrm{kPa}$ (100 PSI), fechando o sistema no momento que o manômetro atingisse a marca de $344,73 \mathrm{kPa}$ (50 PSI), simultaneamente era coletada a rotação do eixo com o auxílio de um tacômetro digital.

Para todas as posições do bico injetor posicionado, conforme a Figura 7, foram realizados 2 ou 3 testes, sempre utilizando a mesma variação de pressão conforme abordado anteriormente. As melhores condições da relação ângulo de entrada na carcaça versus rotação do eixo para cada posição podem ser observadas na Tabela 2.

Tabela 2 - Relação do ângulo de entrada versus rotação do eixo para rotor de $300 \mathrm{~mm}$ de diâmetro e diâmetro interno do injetor de alimentação de $6 \mathrm{~mm}$

\begin{tabular}{ccc}
\hline Posição & Ângulo & RPM \\
\hline 1 & $30^{\circ}$ & 3300 \\
2 & $15^{\circ}$ & 4280 \\
3 & $10^{\circ}$ & 4400 \\
4 & $90^{\circ}$ & 3919 \\
$\mathbf{5}$ & $\mathbf{1 5}^{\circ}$ & $\mathbf{4 8 8 9}$ \\
6 & $30^{\circ}$ & 4549 \\
7 & $45^{\circ}$ & 4474 \\
8 & $30^{\circ}$ & 4850 \\
9 & $15^{\circ}$ & 4815 \\
10 & $5^{\circ}$ & 4800 \\
11 & $15^{\circ}$ & 4513 \\
12 & $15^{\circ}$ & 4717 \\
13 & $15^{\circ}$ & 4404 \\
\hline
\end{tabular}

Fonte: dos autores (2016).

Com base nos valores da Tabela 2, a melhor condição encontra-se com ângulo de $15^{\circ}$ na posição 5 . Desta forma, determinou-se esta como a posição de 
trabalho do injetor para os testes a seguir e validação do sistema. Este estudo realizado não se encontra apresentado na literatura pesquisada.

\subsubsection{Determinação do ângulo de saída na carcaça}

Após a determinação do ângulo de entrada, foi possível a determinação do ângulo de saída. Para a realização desta atividade, foram levadas em consideração às melhores configurações obtidas até aqui.

Realizou-se um teste experimental para visualizar o escoamento do fluido após o contato com a pá do rotor, com a posição do ângulo de entrada de trabalho determinado, o jato de pressão do injetor foi acionado movimentando o sistema. Com o auxílio de um suporte, foram amarrados fios, foi posicionado este suporte no caminho do escoamento do fluido, assim, possibilitando uma melhor visualização da direção que o fluido percorre após o contato com a pá do rotor. Este teste auxiliou na determinação do ângulo de saída da carcaça, a Figura 9 apresenta o teste realizado.

Figura 9 - Visualização do caminho do escoamento do fluido

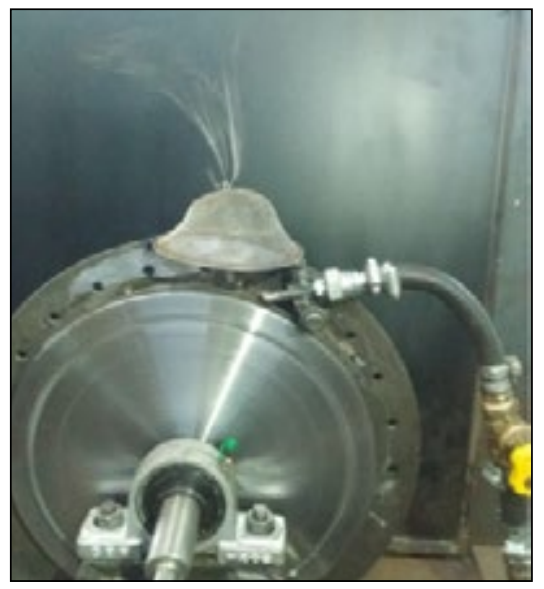

Fonte: dos autores (2016).

\subsubsection{Validação do diâmetro do bico injetor}

Para a validação do melhor diâmetro interno do injetor, diâmetro que está diretamente associado à vazão e velocidade cinética do escoamento e que são propriedades indispensáveis para um melhor aproveitamento da energia disponível no fluido, foram utilizados terminais de sistemas hidráulicos comerciais, nos quais possuem diâmetros padrões e que foram utilizados no projeto devido à alta disponibilidade no mercado. Os diâmetros internos selecionados foram 4,6 , e $9 \mathrm{~mm}$. 
Na posição pré-determinada do ângulo de entrada e com o auxílio do gabarito de articulação conforme a Figura 9 foi possível adaptar três terminais com diferentes diâmetros internos conforme a Figura 10.

Figura 10 - Terminais utilizados para a determinação do diâmetro interno do bico injetor

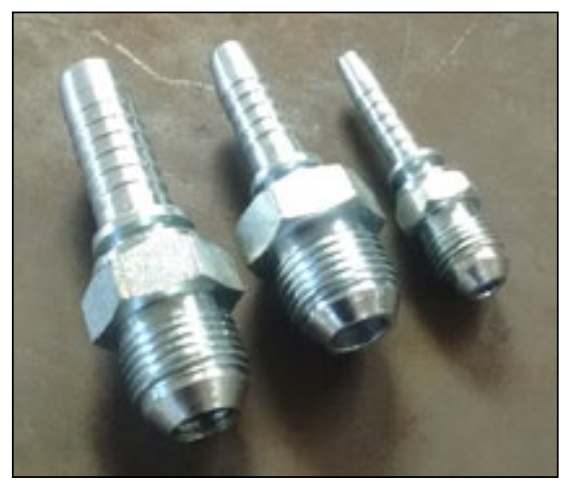

Fonte: dos autores (2016).

Conforme abordado anteriormente, o compressor utilizado nos testes, não possui configurações para manter a pressão constante, ou seja, foi adotada a mesma variação de pressão para todos os testes realizados. A Tabela 3 apresenta os testes realizados.

Tabela 3 - Testes para validação do diâmetro interno do injetor

\begin{tabular}{c|c|c|c|c}
\hline Teste & $\begin{array}{c}\text { Variação de } \\
\text { pressão kPa }\end{array}$ & $\begin{array}{c}\text { Diâmetro interno } \\
\text { do bico injetor em } \\
\text { (mm) }\end{array}$ & $\begin{array}{c}\text { Rotação máxima } \\
\text { no eixo }\end{array}$ & Tempo \\
\hline 1 & $689,47-334,73$ & 4 & 3000 & $04: 52$ min \\
\hline 2 & $689,47-334,73$ & 6 & 6400 & $48 \mathrm{~s}$ \\
\hline 3 & $689,47-334,73$ & 9 & 4090 & $21 \mathrm{~s}$ \\
\hline & & & & \\
\hline
\end{tabular}

Fonte: dos autores (2016).

Conforme os dados da Tabela 3, com todos os diâmetros, quando o manômetro do injetor atingisse $689,47 \mathrm{kPa}$, o sistema era acionado com o eixo livre. Foi monitorado o tempo e a rotação até que o manômetro atingisse 334,73 $\mathrm{kPa}$. Com estas informações, chegou-se à conclusão que o diâmetro do teste 2, apresentou a melhor condição de aproveitamento da energia do fluido. Embora o tempo seja menor, o que significa maior velocidade do escoamento, o mesmo apresentou melhores condições para uma maior geração de potência no eixo 
devido à alta rotação. Este parâmetro foi selecionado e utilizado nos testes a seguir.

\subsubsection{Equipamentos para a validação da potência mecânica}

Para a validação da potência mecânica da máquina de fluxo tangencial de baixo custo, foi utilizado um freio eletromagnético da marca Delorenzo DL 30300 e uma unidade de medição digital de energia mecânica da mesma marca com codificação DL 10055N, Figuras 11 e 12 respectivamente. Estes equipamentos são utilizados no mercado de trabalho para a medição de torque no eixo de motores por meio de uma célula de carga, velocidade de rotação e medições de energia mecânica fornecida ao sistema.

Figura 11 - Freio eletromagnético da marca Delorenzo DL 30300

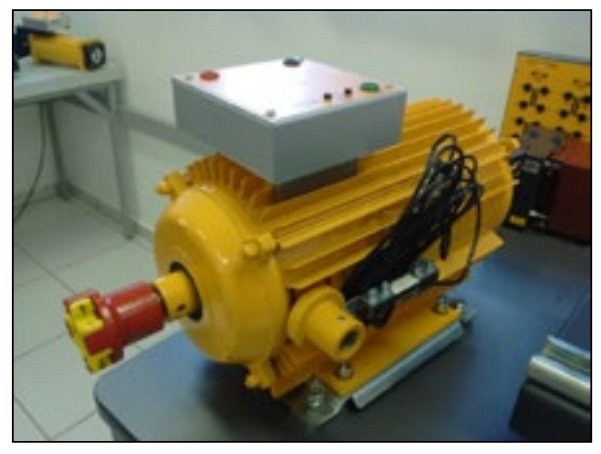

Fonte: dos autores (2016).

Figura 12 - Unidade de medição digital de energia mecânica DL 10055N

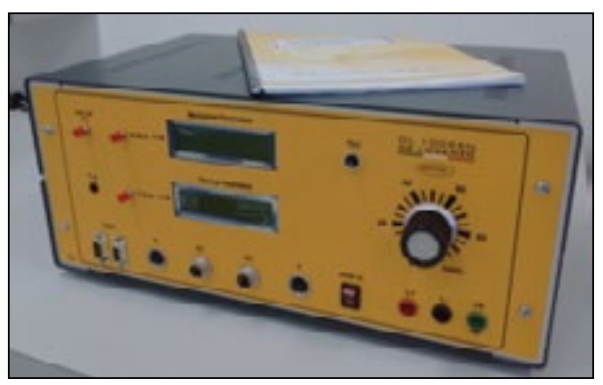

Fonte: dos autores (2016).

Uma bancada de testes foi montada para acoplar o freio eletromagnético na máquina de fluxo tangencial. Um acoplamento foi utilizado para conectar o eixo da máquina de fluxo no eixo do freio eletromagnético. Na Figura 13 observa-se a bancada de testes montada. 
Figura 13 - Bancada de testes para validação de potência mecânica.

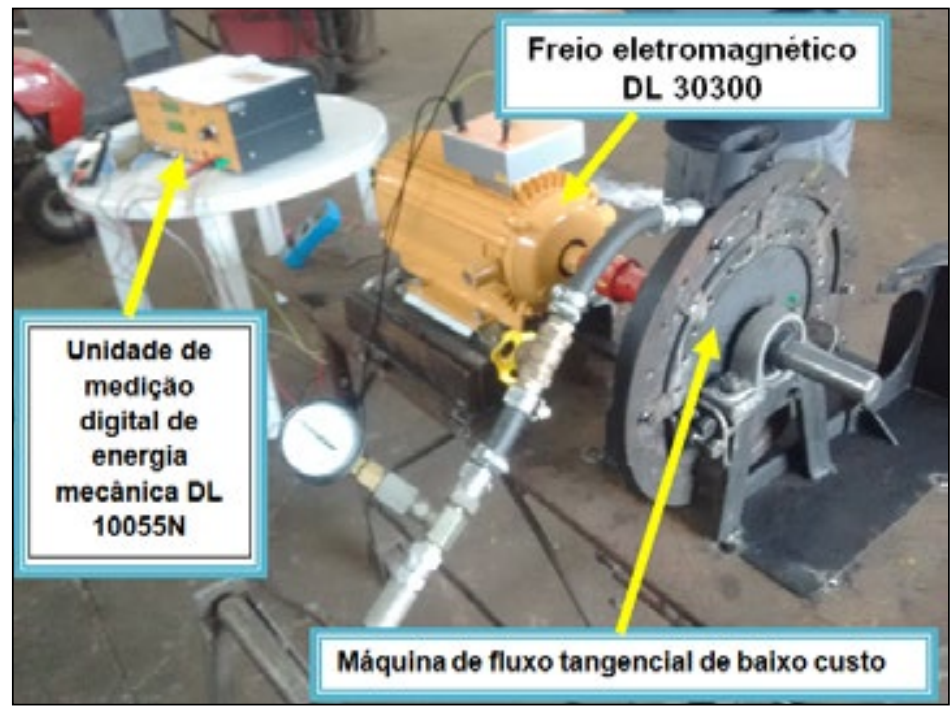

Fonte: dos autores (2016).

A unidade de medição digital de energia mecânica possui um display que fornece a medida direta das principais informações que são relevantes para a validação do projeto em questão, na Figura 14 pode-se observar a configuração do display, na qual informa os parâmetros mecânicos dos testes realizados.

Figura 14 - Display com informações dos parâmetros mecânicos

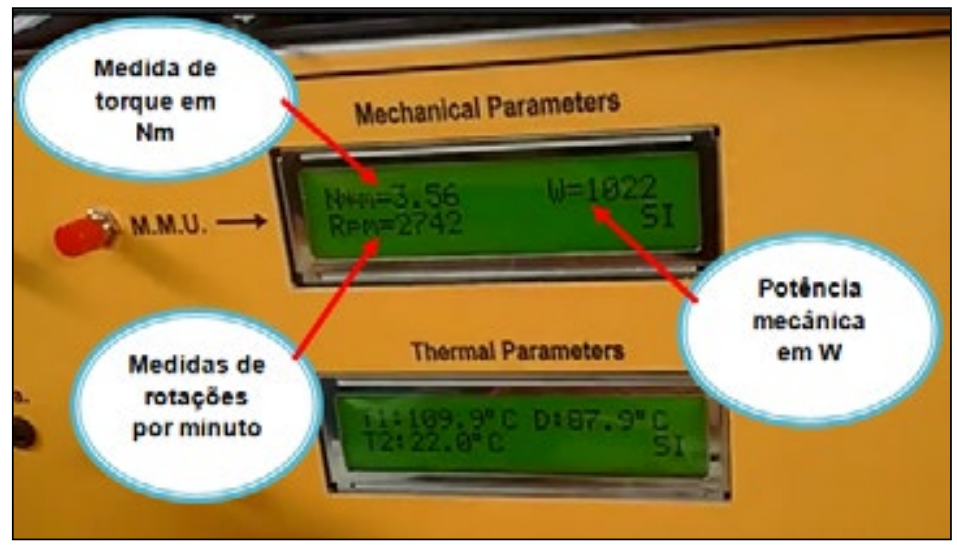

Fonte: dos autores (2016). 


\section{RESULTADOS E DISCUSSÕES}

De acordo com as informações dos catálogos disponíveis sobre o freio eletromagnético utilizado na validação do sistema, a máxima rotação permitida do equipamento é de 5000 rotações por minuto. Conforme os requisitos do projeto e o dimensionamento básico realizado, todos os testes foram realizados com 3500 rotações por minuto. Optou-se por três testes, que foram realizados apenas com eixo acoplado no freio eletromagnético conforme a Figura 13.

Foram utilizadas três faixas de pressão para todos os testes, teste 1 (517,10 kPa (75PSI)); teste 2 (861,84 kPa (125PSI)); teste $3(1.206,58 \mathrm{kPa}(175 \mathrm{PSI}))$.

Os testes foram realizados de acordo com os seguintes passos: 1. Acionamento do injetor; 2. Monitoramento no display até atingir 3500 RPM; 3. Coleta de dados; 4 . Desativação do injetor. Com isso, pôde ser realizada uma análise das interações entre Pressão versus Rotações Por Minuto, Pressão versus Potência Mecânica e Pressão versus Torque no Eixo, o que é possível verificar através das Figuras 15, 16 e 17.

A Figura 15 apresenta os três testes realizados estabelecendo a relação entre a variação de pressão e a rotação do eixo. O comportamento do gráfico mostra que quanto maior a pressão, maior a rotação no eixo.

Figura 15 - Gráfico que apresenta o comportamento da rotação do eixo da máquina de fluxo tangencial de acordo com a variação de pressão

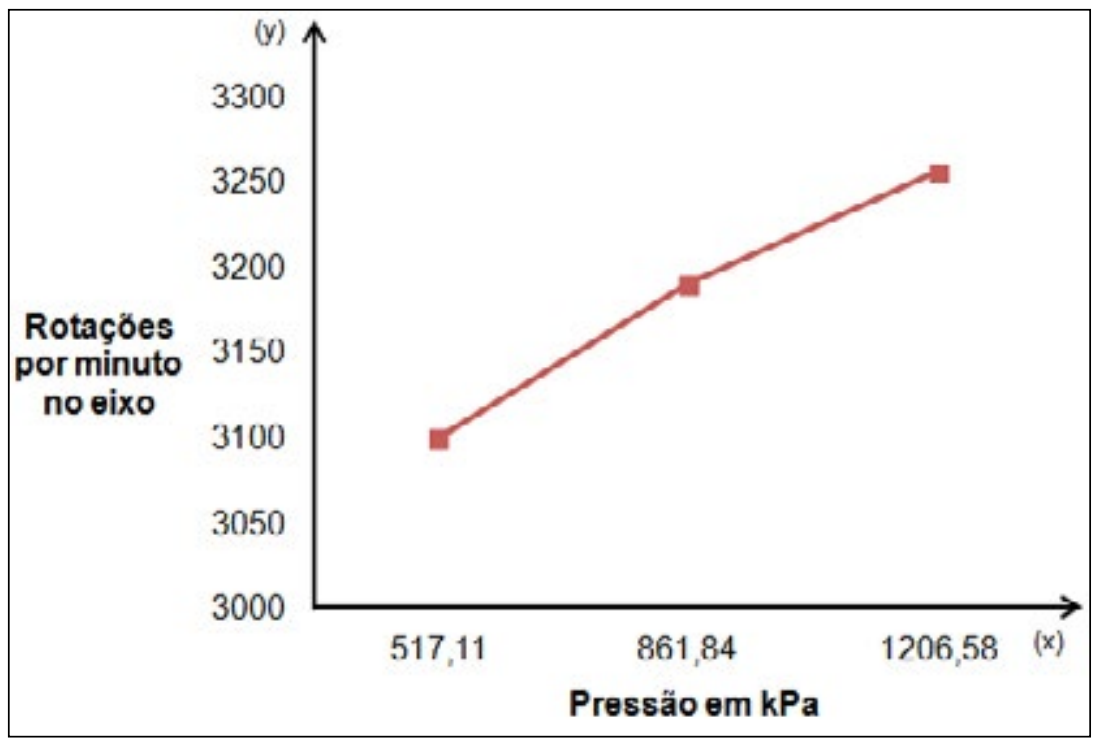

Fonte: dos autores (2016).

Também de acordo com os valores da Figura 16, no gráfico percebese que com os três testes realizados, o aumento da potência é proporcional ao 
aumento da pressão. Esta característica se deve ao fato de que quanto maior é a pressão do ar de alimentação da máquina de fluxo, maior é a energia disponível para ser convertida. Com isso, o objetivo inicial do estudo foi alcançado, já que o projeto foi validado em todas as situações, nas quais atingiram valores superiores a $1000 \mathrm{~W}$ de potência mecânica no eixo, mesmo no teste de menor pressão (Teste 1).

Figura 16 - Potência mecânica no eixo (W), de acordo com a variação de pressão

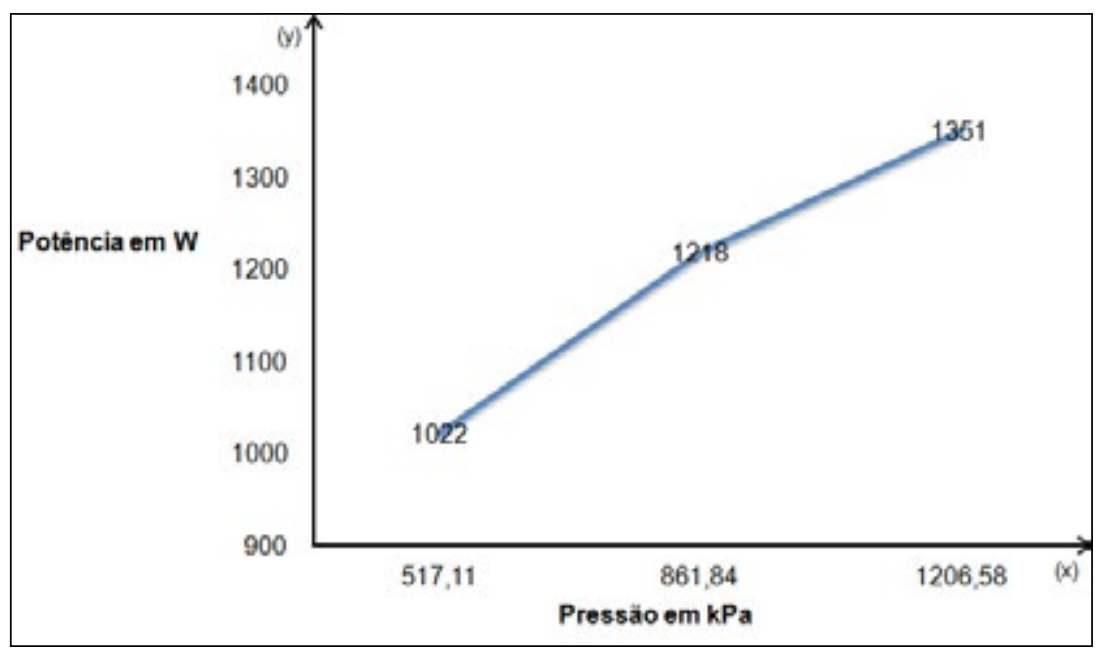

Fonte: dos autores (2016).

A Figura 17 apresenta um gráfico com os valores de torque no eixo de acordo com a pressão aplicada. A rotação no eixo para todos os casos foi padrão, ou seja, 3500 rotações por minuto. 
Figura 17 - Comportamento do torque no eixo de acordo com a variação de pressão

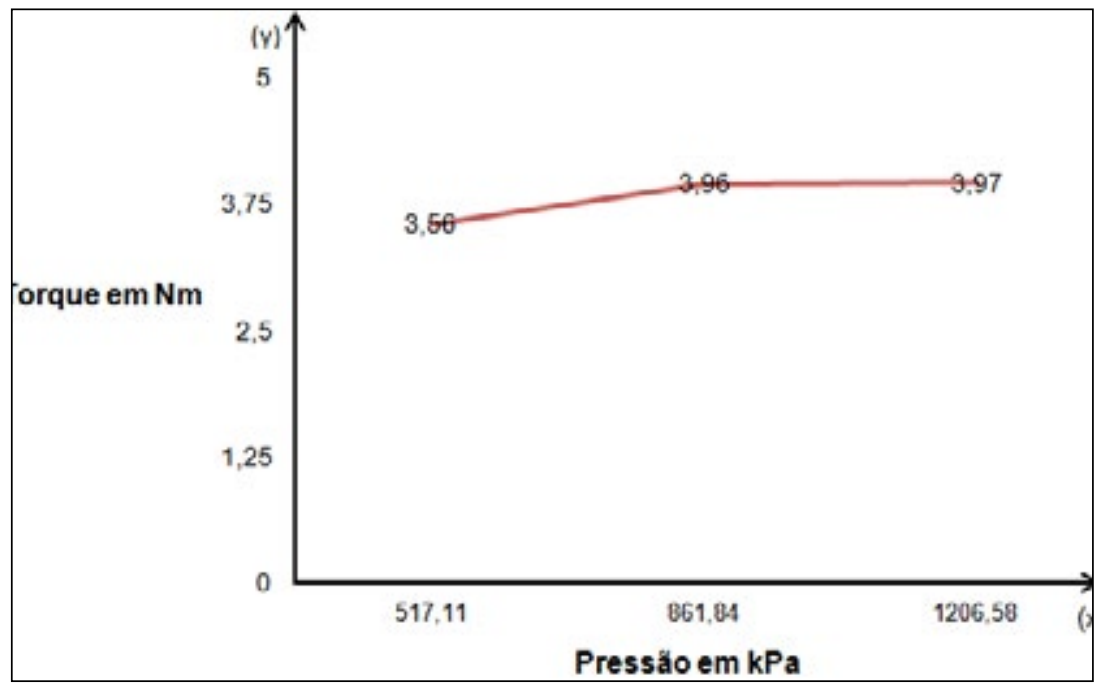

Fonte: dos autores (2016).

\subsection{Análise da eficiência do sistema}

A eficiência baseada na primeira lei da termodinâmica da máquina de fluxo pode ser obtida relacionando o torque medido através do freio eletromagnético, com torque ideal calculado no dimensionamento básico, ou seja, são duas energias de mesma natureza (energia mecânica).

Os valores do torque ideal que seria gerado no eixo se não houvesse perdas no processo, foram determinados através do produto entre e força tangencial e o raio do rotor $\left(\mathrm{T}=\mathrm{Fr}_{\text {rotor }}\right)$, para cada situação os valores encontramse na Tabela 1. O torque medido são os valores coletados durante os testes, e que se encontram na Figura 17.

$$
\begin{aligned}
& \text { Eficiência Teste } 1=\frac{\text { Torque medido }}{\text { Torque ideal }}=\frac{3,56 \mathrm{Nm}}{4,38 \mathrm{Nm}} \times 100=81,11 \% \\
& \text { Eficiência Teste } 2=\frac{\text { Torque medido }}{\text { Torque ideal }}=\frac{3,96 \mathrm{Nm}}{7,31 \mathrm{Nm}} \times 100=54,17 \% \\
& \text { Eficiência Teste } 3=\frac{\text { Torque medido }}{\text { Torque ideal }}=\frac{3,97 \mathrm{Nm}}{10,23 \mathrm{Nm}} \times 100=38,79 \%
\end{aligned}
$$

De acordo com os valores da eficiência baseada na primeira lei, observase que, mesmo sabendo que existem perdas de energia durante o processo, $\mathrm{o}$ teste 1 é a situação que apresenta a melhor condição de trabalho. Os testes 2 e 3 
estão trabalhando com eficiência de $54,17 \%$ e $38,79 \%$, respectivamente, o que indica uma perda de energia considerável durante o processo.

A eficiência, baseada no balanço de exergia, relaciona a energia disponível no sistema, que pode ser convertida em trabalho, com a energia real produzida pelo sistema, medida através de testes experimentais. Para o presente trabalho, o efeito útil desejado é a potência mecânica no eixo. A energia disponível é a energia cinética do escoamento. Portanto, para esta máquina de fluxo, a eficiência baseada no balanço de exergia pode ser calculada pela razão entre a potência medida e a taxa de variação de exergia, calculada anteriormente no dimensionamento básico, os quais os valores encontram-se na Tabela 1. Os valores da eficiência através do balanço de exergia, para cada teste realizado, encontram-se nos cálculos a seguir:

$$
\begin{aligned}
& \text { Eficiência Teste } 1=\frac{\text { Potência medida }}{\Delta \varphi}=\frac{1022 \mathrm{~W}}{4323 \mathrm{~W}} \times 100=18,63 \% \\
& \text { Eficiência Teste } 2=\frac{\text { Potência medida }}{\Delta \varphi}=\frac{1218 \mathrm{~W}}{9454,19 \mathrm{~W}} \times 100=12,88 \% \\
& \text { Eficiência Teste } 3=\frac{\text { Potência medida }}{\Delta \varphi}=\frac{1351 \mathrm{~W}}{13438,67 \mathrm{~W}} \times 100=10,01 \%
\end{aligned}
$$

Com base na Figura 18, que contém um gráfico com um comparativo entre as eficiências baseadas na primeira lei da termodinâmica e as eficiências do balanço de exergia, percebe-se que a melhor condição para este protótipo também se encontra no teste 1 , no qual se encontra a menor pressão, mas que atinge, de forma satisfatória, o objetivo inicial do estudo que foi a geração de potência mecânica no eixo de $1000 \mathrm{~W}$, isto se deve pelo maior aproveitamento da potência útil oferecida ao processo. 
Figura 18 - Comparativo da eficiência baseada na primeira lei da termodinâmica com a eficiência do balanço de exergia

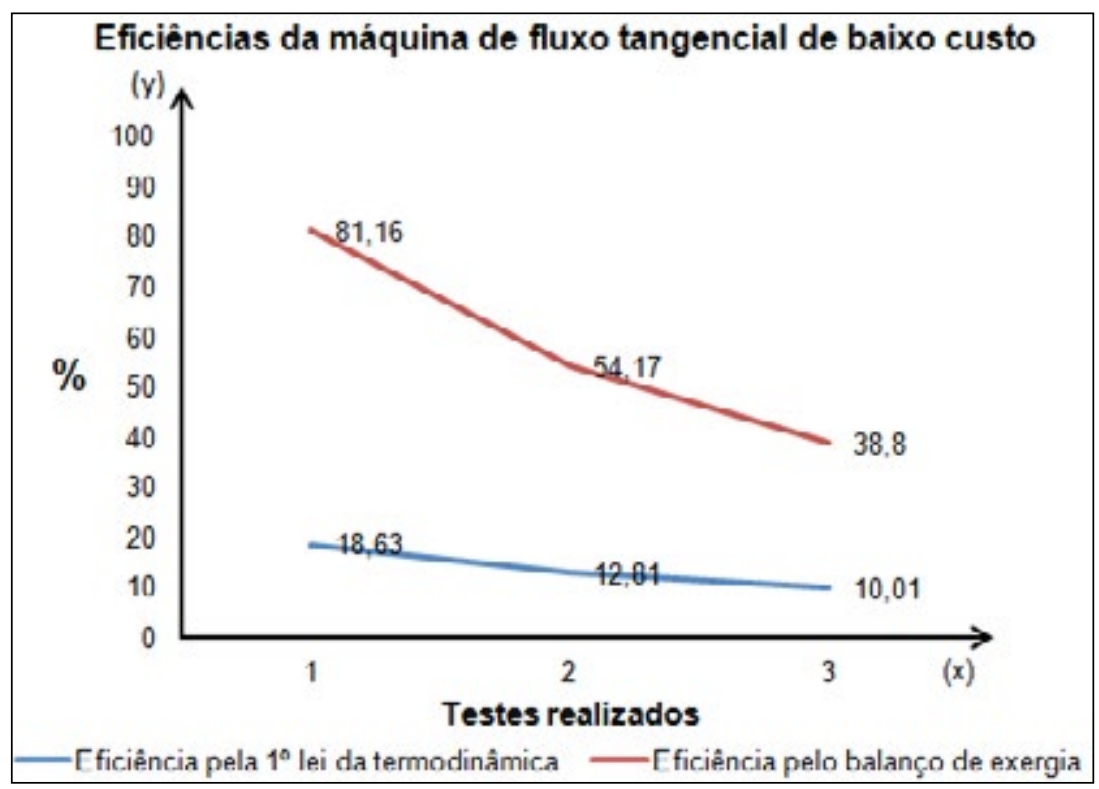

Fonte: dos autores (2016).

Os testes 2 e 3 apresentaram baixa eficiência em comparação ao teste 1. De acordo com a visão do autor, este comportamento se deve ao fato de haver muitas perdas da energia do escoamento do fluido em relação a pá do rotor. Acredita-se que o perfil da pá do rotor precisa possuir uma configuração geométrica específica para as velocidades e massas específicas dos casos 2 e 3, e que isso serve de motivação para estudos futuros. Acreditando-se que haverá um melhor aproveitamento e maior eficiência do sistema para estas duas situações.

Um bom exemplo, são os projetos das turbinas hidráulicas tangenciais Pelton, amplamente utilizadas para a geração de energia elétrica. Estas turbinas operam com uma eficiência de 85 a $95 \%$. Isto só é possível, porque em muitos casos, são projetadas de acordo com a vazão e queda de água disponível nos locais onde são instaladas. Para que esta eficiência seja alcançada, também é necessário um alto investimento em projeto e processos de fabricação. Comparando a eficiência das turbinas Pelton com o modelo proposto no presente estudo, fica evidente que as pás do rotor precisam ser projetadas de acordo com as diferentes condições de operação, visando um melhor aproveitamento da velocidade cinética do escoamento, consequentemente aumentando a sua eficiência. 


\section{CONCLUSÕES}

Este trabalho apresentou as principais fases de um projeto de uma máquina de fluxo tangencial de baixo custo, desde a fase conceitual, dimensionamento inicial, processos de fabricação e desenvolvimento de bancadas de testes para a validação do projeto proposto. Foi possível uma análise e entendimento prático das melhores configurações de todos os principais elementos construtivos que compõem uma máquina de fluxo tangencial, os quais foram validados através de experimentos práticos, com auxílio de gabaritos e equipamentos desenvolvidos paralelamente e que foram indispensáveis para a otimização do modelo proposto.

Com base nos dados obtidos, testes e experimentos práticos realizados, conclui-se que o projeto alcançou resultados expressivos levando em consideração o baixo investimento. Todos os objetivos determinados inicialmente foram alcançados, dos quais o principal objetivo foi a geração de potência mecânica no eixo de 1000 W. De acordo com os testes realizados, verificou-se que a máquina de fluxo gera cerca de $1022 \mathrm{~W}$ quando a pressão do ar de alimentação é $517,11 \mathrm{kPa}$, nestas condições a máquina apresenta uma eficiência de $18,63 \%$. No momento que a pressão passa a ser $861,84 \mathrm{kPa}$, a máquina gera $1218 \mathrm{~W}$, com uma eficiência de $12,88 \%$. Já para a maior pressão do ar de alimentação, $1206,58 \mathrm{kPa}$, a potência gerada é de $1351 \mathrm{~W}$ e a eficiência da máquina é $10,05 \%$. Isto só foi possível através da metodologia proposta, que se demonstrou adequada para atender os objetivos propostos neste trabalho, além de proporcionar uma grande fonte de conhecimento possibilitando que o autor atuasse em todas as fases de um projeto de engenharia mecânica.

\section{Referências}

ÇENGEL, Y. A.; CIMBALA, J. M. Mecânica dos Fluidos: Fundamentos e Aplicações. 3.ed - Porto Alegre: McGraw-Hill, 2015.

ÇENGEL, Yunus A.; BOLES, Michael A. Thermodynamics: an engineering approach. 7. ed. Nova York: McGraw-Hill, 2011. Classificação: 621.43.016=20 C395t (ENG)

FOX, Robert W.; PRITCHARD, Philip J.; MCDONALD, Alan T. Introdução à mecânica dos fluidos. 7. ed. Rio de Janeiro: LTC, 2013. Classificação: 531.3 F793i (CET) de Janeiro: LTC, c2002. Classificação: 53 H188f (CET)

HENN, É. A. L. Máquinas de fluido. $2^{\circ}$ ed. UFSM: 2006.

SOUZA, Z. de. Projeto de Máquinas de Fluxo - Tomo I - Base Teórica e experimental. 1. ed. Rio de Janeiro: Interciência, 2011.

VAN WYLEN, Gordon J.; SONNTAG, Richard E.; BORGNAKKE, Claus. Fundamentos da termodinâmica clássica. São Paulo: Edgard Blücher, 2012. Classificação: 621.43.016 V285f (ENG). 